\title{
Insulin, corticosterone and the autonomic nervous system in animal obesities: a viewpoint
}

\author{
B. Jeanrenaud \\ Laboratoires de Recherches Métaboliques, Faculty of Medicine, University of Geneva, Geneva, Switzerland
}

The article by Dr. Zawalich is very interesting and his working hypothesis, i.e. that "events at the level of the beta cells are the earliest changes occurring in the prediabetic individual", that "enhanced beta-cell responsiveness, a result of increases in vagal and fuel stimulation of the islets, results in hyperinsulinaemia"; that "chronic or at least long-lasting hyperinsulinaemia is then responsible for changes in target tissue sensitivity to the glucose-regulatory effect of insulin", are very much in keeping with data from our and other basic research laboratories [1-4].

The endocrine pancreas. It has been found that the endocrine pancreas of 17-day-old preobese pups tested before weaning (i.e. before they become visibly obese) had a greater insulin output in response to glucose or arginine than age-matched control animals. This abnormality was returned to normal by prior acute administration of atropine. As atropine did not change substrate-induced insulin output of control pups, these data clearly indicate that an overactive vagus nerve was responsible for substrate-induced insulin oversecretion of the preobese group $[5,6]$.

In keeping with this conclusion, a short-acting electrical stimulation of the cervical vagus nerve produced an insulin output that was more than 10 times higher in adult genetically obese fa/fa rats than in controls [5].

Furthermore, a short-acting electrical stimulation of the vagus nerve carried out immediately before in-

Corresponding author: Professor B. Jeanrenaud, Laboratoires de Recherches Métaboliques, Faculty of Medicine, University of Geneva, 64 Avenue de la Roseraie, CH-1211 Geneva 4, Switzerland

Abbreviations: VMH, Ventromedial hypothalamus; LPL, lipoprotein lipase activity; NPY, neuropeptide y; CRF, corticotropin releasing factor; i.c, v., intracerebroventricular; GLUT, glucose transporter. travenous glucose administration potentiated glucose-induced insulin secretion in both adult normal and genetically obese rats, but to a level that was two times higher in the obese than in the normal group [5].

Finally, isolated perfused pancreases from genetically obese rats (fa/fa) secreted almost ten times more insulin in response to arginine than pancreases from normal rats. Superimposed infusion of atropine had no effect on arginine-induced insulin secretion by pancreases from lean rats but decreased that of obese rats, thereby suggesting the presence of increased cholinergic activity in pancreases of obese rats [5].

In a model of experimental obesity (ventromedial hypothalamic lesions, VMH-lesioned rats) the amount of insulin or glucagon released during methacholine infusion (a muscarinic agonist) was five and two times greater, respectively, in isolated pancreases from experimentally obese rats than in those of controls, effects that were completely abolished by the superimposed infusion of atropine, thus demonstrating the specificity of the methacholine effect on the cholinergic system [7].

When basal insulinaemia was somewhat increased (by 1.15 fold) in young (21-day-old unweaned) genetically obese animals, fat accretion was increased and muscles were not insulin resistant, but insulin overresponsive [8].

Peripheral hormones and metabolism. It has been shown [9] that in adipocytes from 16-day-old preobese unweaned rats, GLUT4 mRNA and protein levels of adipocytes were more than twice those of controls [9]. Although these data were interpreted as being in agreement with a genotype regulatory effect on GLUT4 [9], subsequent data reported that basal insulinaemia was increased in preobese pups of the same age [10]. Furthermore, substrate-induced insulin output was not measured in these preobese ani- 
mals, but was likely to be increased at this phase of the syndrome, as it was in the 17-day-old preobese pups mentioned above $[5,6]$.

It is important to emphasise that great efforts have been made to attempt to detect the earliest abnormalities of obesity syndromes. One should be aware, however, that a given alteration cannot always be accompanied by measurements of the final output needed to prove the relevance of the alteration in question. Thus, brown adipose tissue thermogenesis capacity (as assessed by the binding of guanosine $5^{\prime}$ diphosphate to isolated mitochondrial membranes) was lower, at 2 days of age, in genetically preobese $\mathrm{fa} / \mathrm{fa}$ pups compared with their normal littermates [11]. This strongly suggested the early occurrence of alterations in the central regulation of the autonomic nervous system, bearing, in this particular case, on the efferent sympathetic limb innervating the brown adipose tissue and the energy dissipating mechanisms thereof. Although not testable, such a defect could affect the endocrine pancreas, thereby alleviating the inhibitory effect of the sympathetic nervous system on insulin output and favouring insulin oversecretion. At 10 days of age the fa/fa pups showed a decrease in the P32'000 uncoupling protein mRNA levels, a protein responsible for the energy dissipation as heat [12]. At this age basal hyperinsulinaemia of the fa/fa was present [10] and could be the result of a central nervous system alteration of the regulation of the autonomic nervous system which affects both the sympathetic efferents (which are decreased in genetic fa/fa obesity), as well as the parasympathetic efferents (which are increased in genetic fa/fa obesity) as reviewed elsewhere [13].

Even if basal insulinaemia is seemingly unchanged in very young genetically preobese pups, basal insulin levels may no longer oscillate, i.e. be "clamped" throughout the day, a defect that is obvious when obesity syndromes are overt $[14,15]$. The importance of the rhythmicity of hormones such as insulin and corticosterone in exerting their physiological role has been emphasised, as has been the pathological influence of the disappearance of this circadian rhythm [16-18]. The view that seemingly normal but "clamped" basal insulinaemia may be enough to stimulate adipose tissue metabolic activity is provided by the following example: normal rats were each infused for 4 days with insulin (1 unit per day) via a subcutaneously implanted minipump delivering the hormone. At the end of this experimental period, basal insulinaemia was the same in the control and the "insulinised" groups and there was no intergroup difference in glycaemia. Despite such lack of increase in basal insulinaemia, the in vivo insulin-stimulated glucose utilisation index of white adipose tissue (measured with the labelled 2-deoxyglucose uptake technique) was much more insulin responsive (about 3 times) in the "insulinised" than in the control group [19].
This possibility is in keeping with the data obtained in VMH-lesioned rats [20]. One week after the lesions, basal plasma insulin levels were identical to those of controls, but adipose tissue GLUT4 mRNA and protein levels were markedly higher in VMH-lesioned obese than in control rats, as were fatty acid synthase, acetyl-CoA carboxylase mRNA levels and enzymatic activities [20]. Note that at this age or even earlier, VMH-lesioned rats are characterised by increases in substrate-induced insulin output [21], increases in basal and overall as well as adipose tissue insulin-stimulated glucose utilisation, increases in glucose carbon conversion into lipid $[14,20]$. These data are compatible with the concept that measurements of basal insulinaemia only may not be an adequate index of the degree of insulin to which 1week VMH-lesioned rats, possibly very young preobese fa/fa pups, are actually exposed on a daily basis. The data are also compatible with the concept that insulin plays an important role in the metabolic changes in adipose tissue and muscles as just summarised. Between days 1 and 7 of age, genetically preobese pups are not hyperphagic [22], they become chemically obese [10] and the activity of adipose tissue glucose transport, of several enzymes involved in fat accretion (e.g. fatty acid synthase, lipoprotein lipase) are augmented in white adipose tissue in particular $[9,23-26]$. These changes are probably not related to gene(s) up-regulating adipose tissue metabolic activity, but are possibly and initially due to the existence of a clamped normoinsulinaemia with undetected peaks of the hormone, followed (from 10 days onward in preobese fa/fa pups) by actual hyperinsulinaemia [10]. This viewpoint is in keeping with the interesting study showing that the blood flow in pancreatic islets from genetically obese fa/fa rats (as well as from VMH-lesioned rats) is increased compared to respective controls. Islet blood flow was further shown to be under the stimulatory influence of the vagus nerve and the inhibitory influence of the sympathetic outflow via the $\alpha_{2}$-adrenergic receptor. Although increased islet blood flow was studied in adult obese rats, early alterations in the regulation of the autonomic system $[7,11,12]$ controlling this process could contribute to "clamp" insulinaemia in preobese rats, to subsequently favour the insulin oversecretion observed in adult obese rats [27].

Increases in adipose tissue lipoprotein lipase activity (LPL) are detectable by day 7 in fa/fa pups, before the onset of overt hyperinsulinaemia [23, 24], although basal insulinaemia could be clamped as just mentioned. At 28 days of age the young genetically obese fa/fa rats have marked increases in LPL activity and are hyperinsulinaemic $[23,26]$. Enlarged adipocyte of young fa/fa rats also have marked increase in LPL activity (per cell or per cell area), LPL secretion and LPL turnover [28], alterations which are not due to a specific abnormality of the LPL gene expres- 
sion or synthesis, but to a generalised increase in total RNA levels and generalised increase in protein synthetic activity [28]. The latter may also be responsible for the reported increase in the number of glucose transporters of adipose tissue from young genetically obese rats [29]. Thus, enhanced responsiveness of adipose tissue to insulin appears to be an important feature, possibly of unweaned preobese rats, certainly of young genetically obese rats, and seems related to sustained hyperinsulinaemia [30] as, in the obese group, both hyperinsulinaemia and increased adipose tissue responsiveness to insulin remain elevated even during fasting [31] or during pair-feeding [32]. The cause of the early increase in adipose tissue (possibly muscle) insulin responsiveness of preobese animals is unknown, but is likely to be due to changes in the activity of the autonomic nervous system, with combined increased parasympathetic and decreased sympathetic efferents $[13,33]$ that would "prime" or sensitise not only islets to the level of glucose [34], but potentially adipose tissue to that of insulin.

As mentioned above, when hyperinsulinaemia is moderate in preobese unweaned genetically obese rats, muscle is not resistant but overresponsive to the hormone [8]. Muscle insulin resistance is present when basal insulinaemia is increased by about two fold and it is thereafter positively correlated with the degree of the prevailing hyperinsulinaemia $[8,35]$. Due to these observations, it can be concluded that muscle insulin resistance appears early in the development of the genetic obesity syndrome but is not a primary event $[8,36,37]$. The pathological relevance of hyperinsulinaemia in obesity-insulin resistance syndromes is further suggested by experiments carried out with normal rats infused for 4 days via subcutaneously implanted minipumps delivering the hormone, while maintaining euglycaemia. Similar observations were made in 7-day "insulinised" normal rats [38]. Such "insulinisation" has divergent effects on adipose tissue and the muscle mass: while "insulinisation" renders adipose tissue more responsive to acute insulin when considering glucose uptake $[39,40]$, glucosetransporter concentration [40] and lipogenesis [39], it produces muscle insulin resistance, the mechanism of which appears to be decreased levels of GLUT4 mRNA and protein in skeletal muscle $[39,40]$.

The lack of hypoglycaemia in the face of hyperinsulinaemia in genetically obese rodents could be due to hyperinsulinaemia-induced early onset of muscle insulin resistance $[8,36]$, also observed in normal humans exposed for $20 \mathrm{~h}$ to hyperinsulinaemia-normoglycaemia [41]. Muscle insulin resistance can also be due to the existence of a concomitant overactive hypothalamo-pituitary adrenal axis [42-44] which, via increased glucocorticoid output, also contributes to producing muscle insulin resistance [45]. In humans, analogous findings have been reported for visceral (central) obesity, as these patients have increased 24-h urinary cortisol excretion and increased activity of the hypothalamo-pituitary-adrenal axis [46]. The combined presence of excess insulin and excess cortisol (or corticosterone) with their own respective effects, together with their synergistic interactions in stimulating lipoprotein lipase activity in particular [47] may well constitute the main basis for the neuroendocrine aetiological basis of obesity.

A common feature linking hyperinsulinaemia and hypercorticism could be a series of dysregulations of neuropeptides [48]. Hypothalamic corticotropin releasing factor (CRF) and neuropeptide Y (NPY) interact with each other [48]. Hypothalamic NPY levels are high in most of the genetically obese rodents [49-55].

Of interest is the observation that intracerebroventricular (i.c.v.) administration of NPY to normal rats for 1 week reproduces most of the hormonal and metabolic alterations observed in genetically obese rodents: basal and substrate-induced hyperinsulinaemia, mild hypercorticism, increased liver and adipose tissue lipogenic activities, increased adipose tissue glucose transport and glucose transporter (mRNA and protein) levels, together with muscle insulin resistance [56-58]. The hyperphagia produced by the i.c.v. infused NPY appears to be an aggravating rather than a causative factor, as most changes observed with i.c.v. NPY administration to normal rats are present when hyperphagia is prevented by pairfeeding $[56,57]$. Thus, i.c. v. NPY produces the same divergent effects on adipose tissue and muscles as does "insulinisation" in normal rats, making adipose tissue more and muscles less responsive to an acute insulin challenge. In this respect, the recently reported lack of effect, in the ob/ob mice, of an adipose tissue protein [59] responsible for satiety could place the ob/ob animals in a nutritional state similar to that of fasting [55], thereby being responsible for the known increase in hypothalamic NPY levels of these obese rodents $[52,55]$, with its peripherally altered energy partition toward fat mentioned above.

The concept that the increased insulin output by the pancreatic beta cell is an early change in the prediabetic phase described by Dr. Zawalich does fit with data gathered from animal models. We have proposed that such an early overresponsiveness of the beta cell is of prime importance for the occurrence of both fat accretion and, directly or indirectly, of insulin resistance, the latter also being brought about by some degree of hypercorticism [42, 45]. We have shown that the overresponsiveness of the endocrine pancreas of obese rodents could be of central (CNS) origin $[1,13,35,60,61]$. Whether this is the case for obese non-insulin-dependent diabetic (NIDDM) patients in general, for obese NIDDM patients with central (i.e. abdominal) obesity in particular, is a challenge that is open for clinical researchers to prove or disprove. 


\section{References}

1. Jeanrenaud B (1985) An hypothesis on the aetiology of obesity: dysfunction of the central nervous system as a primary cause. Diabetologia 28: 502-513

2. Bray GA (1989) Genetic and hypothalamic mechanisms for obesity - finding the needle in the haystack. Am J Clin Nutr 50: 891-902

3. Bray GA (1990) Obesity - a state of reduced sympathetic activity and normal or high adrenal, activity (the autonomic and adrenal hypothesis revisited). Int J Obes 14 [Suppl 3]: 77-92

4. Bodkin NL, Hannah JS, Ortmeyer HK, Hansen BC (1991) Obesity and hyperlipidemia in the rhesus monkey: interactions with the development of type 2 diabetes. In: Shafrir E (ed) Frontiers in diabetes research. Lessons from animal diabetes III. Smith-Gordon and Company Ltd, London, pp. 644-649

5. Rohner-Jeanrenaud F, Hochstrasser AC, Jeanrenaud B (1983) Hyperinsulinemia of preobese and obese fa/fa rats is partly vagus nerve mediated. Am J Physiol 244: E317E322

6. Rohner-Jeanrenaud F, Jeanrenaud B (1985) Involvement of the cholinergic system in insulin and glucagon oversecretion of genetic pre-obesity. Endocrinology 116: 830834

7. Rohner-Jeanrenaud F, Jeanrenaud B (1981) Possible involvement of the cholinergic system in hormonal secretion by the perfused pancreas from ventromedial-hypothalamic lesioned rats. Diabetologia 20: 217-222

8. Zarjevski N, Doyle P, Jeanrenaud B (1992) Muscle insulin resistance may not be a primary etiological factor in the genetically obese fa/fa rat. Endocrinology 130: 15641570

9. Hainault I, Guerre-Millo M, Guichard C, Lavau M (1991) Differential regulation of adipose tissue glucose transporters in genetic obesity (fatty rat). Selective increase in the adipose cell/muscle glucose transporter (GLUT4) expression. J Clin Invest 87: 1127-1131

10. Krief S, Bazin R (1991) Genetic obesity: is the defect in the sympathetic nervous system? A review through developmental studies in the preobese Zucker rat. Proc Soc Exp Biol Med 198: 528-538

11. Bazin R, Etève D, Lavau M (1984) Evidence for decreased GDP binding to brown-adipose-tissue mitochondria of obese Zucker (fa/fa) rats in the very first days of life. Biochem J 221: 241-245

12. Ricquier D, Bouillaud F, Toumelin P et al (1986) Expression of uncoupling protein mRNA in thermogenic or weakly thermogenic brown adipose tissue. Evidence for a rapid $\beta$-adrenoreceptor-mediated and transcriptionally regulated step during activation of thermogenesis. J Biol Chem 261: $13905-13910$

13. Jeanrenaud B, Halimi S, Van de Werve G (1985) Neuro-endocrine disorders seen as triggers of the triad: obesity-insulin resistance-abnormal glucose tolerance. Diabetes Metab Rev 1: 261--291

14. Pénicaud L, Rohner-Jeanrenaud F, Jeanrenaud B (1986) In vivo metabolic changes as studied longitudinally after ventromedial hypothalamic lesions. Am J Physiol 250: E662E668

15. Terrettaz J, Cusin I, Etienne J, Jeanrenaud B (1994) In vivo regulation of adipose tissue lipoprotein lipase in normal rats made hyperinsulinemic and in hyperinsulinemic genetically-obese (fa/fa) rats. Int J Obes 18: 9-15

16. Dallman MF (1984) Viewing the ventromedial hypothalamus from the adrenal gland. Am J Physiol 246: R1-R12
17. Dallman MF, Strack AM, Akana SF et al. (1993) Feast and famine: critical role of glucocorticoids with insulin in daily energy flow. Front Neuroendocrinol 14: 303-347

18. Tempel DL, Leibowitz SF (1994) Adrenal steroid receptors: interactions with brain neuropeptide systems in relation to nutrient intake and metabolism. J Neuroendocrinol 6: $479-501$

19. Cusin I, Rohner-Jeanrenaud F, Terrettaz J, Jeanrenaud B (1992) Hyperinsulinemia and its impact on obesity and insulin resistance. Int J Obes 16 [Suppl 4]: S1-S11

20. Cousin B, Agou K, Leturque A, Ferré P, Girard J, Pénicaud $\mathrm{L}$ (1992) Molecular and metabolic changes in white adipose tissue of the rat during development of ventromedial hypothalamic obesity. Eur J Biochem 207: 377-382

21. Berthoud HR, Jeanrenaud B (1979) Acute hyperinsulinemia and its reversal by vagotomy after lesions of the ventromedial hypothalamus in anesthetized rats. Endocrinology 105: 146-151

22. Bell GE, Stern JS (1977) Evaluation of body composition of young obese and lean Zucker rats. Growth 41: 63-80

23. Gruen R, Hietanen E, Greenwood MRC (1978) Increased adipose tissue lipoprotein lipase activity during the development of the genetically obese rat (fa/fa). Metabolism 27 [Suppl 2]: 1955-1966

24. Boulangé A, Planche E, deGasquet P (1979) Onset of genetic obesity in the absence of hyperphagia during the first week of life in the Zucker rat (fa/fa). J Lipid Res 20: 857 864

25. Bazin R, Lavau M (1982) Development of hepatic and adipose tissue lipogenic enzymes and insulinemia during suckling and weaning on to a high-fat diet in Zucker rats. J Lipid Res 23: 839-849

26. Dugail I, Quignard-Boulanger A, Brigant L, Etienne J, Noe L, Lavau M (1988) Increased lipoprotein lipase content in the adipose tissue of suckling and weaning obese Zucker rats. Biochem J 249: $45-49$

27. Atef N, Ktorza/A, Picon L, Pénicaud L (1992) Increased islet blood flow in obese rats: role of the autonomic nervous system. Am J Physiol 262: E736-E740

28. Fried SK, Turkenkopf IJ, Goldberg IJ et al. (1991) Mechanisms of increased lipoprotein lipase in fat cells of obese Zucker rats. Am J Physiol 261: E653-E660

29. Guerre-Millo M, Lavau M, Horne JS, Wardzala LJ (1985) Proposed mechanism for increased insulin-mediated glucose transport in adipose cells from young, obese Zucker rats. Large intracellular pool of glucose transporters. J Biol Chem 260: 2197-2201

30. Pénicaud L, Ferré P, Assimacopoulos-Jeannet $F$ et al. (1991) Increased gene expression of lipogenic enzymes and glucose transporter in white adipose tissue of suckling and weaned obese Zucker rats. Biochem J 279: 303-308

31. Gruen PK, Greenwood MRC (1981) Adipose tissue lipoprotein lipase and glycerol release in fasted Zucker (fa/fa) rats. Am J Physiol 241: E76-E83

32. Cleary MP, Vasselli JR, Greenwood MRC (1980) Development of obesity in Zucker obese (fa/fa) rat in absence of hyperphagia. Am J Physiol 238: E284-E292

33. Woods SC, Porte JR (1974) Neural control of the endocrine pancreas. Physiol Rev 54: 596-619

34. Zawalich WS, Zawalich KC, Rasmussen H (1989) Cholinergic agonists prime the beta-cell to glucose stimulation. Endocrinology 125: 2400-2406

35. Le Marchand Y, Freychet P, Jeanrenaud B (1978) Longitudinal study on the establishment of insulin resistance in hypothalamic obese mice. Endocrinology 102: 74-85

36. Pénicaud L, Ferré P, Terrettaz J et al. (1987) Development of obesity in Zucker rats. Early insulin resistance in mus- 
cles but normal sensitivity in white adipose tissue. Diabetes 36: 626-631

37. McGarry JD (1994) Disordered metabolism in diabetes: have we underemphasized the fat component? J Cell Biochem 55S: 29-38

38. Takao F, Laury M-C, Ktorza A, Picon L, Pénicaud L (1990) Hyperinsulinemia increases insulin action in vivo in white adipose tissue but not in muscles. Biochem $\mathrm{J} 272$ : 255-257

39. Cusin I, Terrettaz J, Rohner-Jeanrenaud F, Jeanrenaud B (1990) Metabolic consequences of hyperinsulinaemia imposed on normal rats on glucose handling by white adipose tissue, muscles and liver. Biochem J 267:99-103

40. Cusin I, Terrettaz J, Rohner-Jeanrenaud F, Zarjevski N, Assimacopoulos-Jeannet F, Jeanrenaud B (1990) Hyperinsulinemia increases the amount of GLUT4 mRNA in white adipose tissue and decreases that of muscles: a clue for increased fat depot and insulin resistance. Endocrinology $127: 3246-3248$

41. Marangou AG, Weber KM, Boston RC, et al (1986) Metabolic consequences of prolonged hyperinsulinemia in humans. Evidence for induction of insulin insensitivity. Diabetes 35: 1383-1389

42. Guillaume-Gentil C, Rohner-Jeanrenaud F, Abramo F, Bestetti GE, Rossi GL, Jeanrenaud B (1990) Abnormal regulation of the hypothalamo-pituitary-adrenal axis in the genetically obese fa/fa rat. Endocrinology 126: 18731879

43. Bestetti GE, Abramo F, Guillaume-Gentil C, RohnerJeanrenaud F, Jeanrenaud B, Rossi GL (1990) Changes in the hypothalamo-pituitary-adrenal axis of genetically obese fa/fa rats: a structural, immunocytochemical, and morphometrical study. Endocrinology 126: 1880-1887

44. Cunningham JJ, Calles-Escandon J, Garrido F, Carr DB, Bode HH (1986) Hypercorticosteronuria and diminished pituitary responsiveness to corticotropin-releasing factor in obese Zucker rats. Endocrinology 118: 98-101

45. Guillaume-Gentil C, Assimacopoulos-Jeannet F, Jeanrenaud B (1993) Involvement of non-esterified fatty acid oxidation in glucocorticoid-induced peripheral insulin resistance in vivo in rats. Diabetologia 36: 899-906

46. Björntorp P (1993) Visceral obesity: a "Civilization Syndrome". Obes Res 1: 206-219

47. Brindley DN (1992) Neuroendocrine regulation and obesity. Int J Obes 16: S73-S79

48. Dryden S, Frankish H, Wang Q, Williams G (1994) Neuropeptide $Y$ and energy balance: one way ahead for the treatment of obesity? Eur J Clin Invest 24: 293-308

49. Bchini-Hooft van Huijsduijnen $O$, Rohner-Jeanrenaud $F$, Jeanrenaud B (1993) Hypothalamic Neuropeptide Y messenger ribonucleic acid levels in pre-obese and genetically obese $(\mathrm{fa} / \mathrm{fa})$ rats; potential regulation thereof by corticotropin-releasing factor. J Neuroendocrinol 5: 381-386

50. Beck B, Burlet A, Nicolas JP, Burlet C (1990) Hyperphagia in obesity is associated with a central peptidergic dysregulation in rats. $J$ Nutr 120: 806-811

51. McKibbin PE, Cotton SJ, McMillan S, Holloway B, Mayers R, McCarthy HD, Williams G (1991) Altered neuropeptide $Y$ concentrations in specific hypothalamic regions of obese (fa/fa) Zucker rats. Possible relationship to obesity and neuroendocrine disturbances. Diabetes 40: 1423-1429

52. Williams G, Cardoso HM, Lee YC, Ball JM, Ghatei MA, Stock MJ (1991) Hypothalamic regulatory peptides in obese and lean Zucker rats. Clin Sci 80: 419-426

53. Sanacora G, Finkelstein JA, White JD (1992) Developmental aspect of differences in hypothalamic preproneuropeptide $\mathrm{Y}$ messenger ribonucleic acid content in lean and genetically obese Zucker rats. J Neuroendocrinol 4: 353-357

54. Williams G, Shellard L, Lewis DE, McKibbin PE, McCarthy HD, Koeslag DG, Russel JC (1992) Hypothalamic neuropeptide-Y disturbances in the obese (cp/cp) JCR-LA corpulent rat. Peptides 13: 537-540

55. Schwartz MW, Marks JL, Sipols AJ, Baskin DG, Woods SC, Kahn SE, Porte DJr (1991) Central insulin administration reduces neuropeptide $\mathrm{Y}$ mRNA expression in the arcuate nucleus of food deprived lean $(\mathrm{Fa} / \mathrm{Fa})$ but not obese $(\mathrm{fa} / \mathrm{fa})$ Zucker rats. Endocrinology 128: 2645-2647

56. Zarjevski N, Cusin I, Vettor R, Rohner-Jeanrenaud F, Jeanrenaud B (1993) Chronic intracerebroventricular Neuropeptide- $Y$ administration to normal rats mimics hormonal and metabolic changes of obesity. Endocrinology 133: $1753-1758$

57. Zarjevski N, Cusin I, Vettor R, Rohner-Jeanrenaud F, Jeanrenaud $B$ (1994) Intracerebroventricular administration of neuropeptide Y to normal rats has divergent effects on glucose utilization by adipose tissue and skeletal muscle. Diabetes 43: 764-769

58. Vettor R, Zarjevski N, Cusin I, Rohner-Jeanrenaud F, Jeanrenaud B (1994) Induction and reversibility of an obesity syndrome by intracerebroventricular neuropeptide $\mathrm{Y}$ administration to normal rats. Diabetologia 37: 1202-1208

59. Zhang Y, Proenca R, Maffei M, Barone M, Leopold L, Friedman JM (1994) Positional cloning of the mouse obese gene and its human homologue. Nature 372: 425-432

60. Doyle P, Rohner-Jeanrenaud F, Jeanrenaud B (1993) Local cerebral glucose utilization in brains of lean and genetically obese (fa/fa) rats. Am J Physiol 264: E29-E36

61. Jeanrenaud B (1994) Central nervous system and peripheral abnormalities: Clues to the understanding of obesity and NIDDM. Diabetologia [Suppl 2] 37: S169-S178 